\title{
Fish Aversion and Attraction to Selected Agrichemicals
}

\author{
João Gabriel Santos da Rosa ${ }^{1} \cdot$ Murilo Sander de Abreu ${ }^{1}$. \\ Ana Cristina Varrone Giacomini ${ }^{1,2} \cdot$ Gessi Koakoski $^{1} \cdot$ Fabiana Kalichak $^{1}$. \\ Thiago Acosta Oliveira ${ }^{1}$ - Heloísa Helena de Alcântara Barcellos ${ }^{1,2}$. \\ Rodrigo Egydio Barreto ${ }^{4}$. Leonardo José Gil Barcellos ${ }^{1,2,3}$
}

Received: 5 April 2016/Accepted: 6 July 2016/Published online: 16 July 2016

(C) Springer Science+Business Media New York 2016

\begin{abstract}
In agriculture intensive areas, fishponds and natural water bodies located in close proximity to these fields receive water with variable amounts of agrichemicals. Consequently, toxic compounds reach nontarget organisms. For instance, aquatic organisms can be exposed to tebuconazole-based fungicides (TBF), glyphosate-based herbicides $(\mathrm{GBH})$, and atrazine-based herbicides $(\mathrm{ABH})$ that are potentially dangerous, which motivates the following question: Are these agrichemicals attractant or aversive to fish? To answer this question, adult zebrafish were tested in a chamber that allows fish to escape from or seek a lane of contaminated water. This attraction and aversion paradigm was evaluated with zebrafish in the presence of an acute contamination with these compounds. We showed that only GBH was aversive to fish, whereas $\mathrm{ABH}$ and $\mathrm{TBF}$ caused neither attraction nor aversion for zebrafish. Thus, these chemicals do not impose an extra
\end{abstract}

Leonardo José Gil Barcellos

lbarcellos@upf.br

João Gabriel Santos da Rosa

joaogabriel.sr@hotmail.com

Murilo Sander de Abreu

abreu.murilo@hotmail.com

Ana Cristina Varrone Giacomini

anacvg@upf.br

Gessi Koakoski

gessikoakoski@yahoo.com.br

Fabiana Kalichak

fabikalichak@hotmail.com

Thiago Acosta Oliveira

thiago_a.oliveira@hotmail.com

Heloísa Helena de Alcântara Barcellos

heloisa@upf.br toxic risk by being an attractant for fish, although TBF and $\mathrm{ABH}$ can be more deleterious, because they induce no aversive response. Because the uptake and bioaccumulation of chemicals in fish seems to be time- and dose-dependent, a fish that remains longer in the presence of these substances tends to absorb higher concentrations than one that escapes from contaminated sites.

Tebuconazole-based fungicides (TBF) and glyphosatebased $(\mathrm{GBH})$ and atrazine-based herbicides $(\mathrm{ABH})$ are largely utilized in agriculture. TBF have been used in several plant cultures or as wood preservatives (Lebokowska et al. 2003). TBF disrupt the endocrine stress response (Cericato et al. 2008, 2009; Koakoski et al. 2014) and provoke severe oxidative stress in fish (Ferreira et al. 2010, 2012, 2013; Toni et al. 2011). GBH and ABH have

Rodrigo Egydio Barreto

rebarreto@yahoo.com

1 Programa de Pós-Graduação em Farmacologia, Universidade Federal de Santa Maria (UFSM), Santa Maria, RS, Brazil

2 Universidade de Passo Fundo (UPF), Campus Universitário do Bairro São José, Caixa Postal 611, CEP 99001-970 Passo Fundo, RS, Brazil

3 Programa de Pós-Graduação em Bioexperimentação, Universidade de Passo Fundo (UPF), Campus Universitário do Bairro São José, Caixa Postal 611, CEP 99001-970 Passo Fundo, RS, Brazil

4 Research Center on Animal Welfare (RECAW), Department of Physiology, Bioscience Institute, Caunesp, Unesp, CEP 18618-970 Botucau, SP, Brazil 
been widely used throughout the world in some cultures that have huge cultivated areas, such as soy and bean. GBH and $\mathrm{ABH}$ have been shown as moderate endocrine disruptors but also act as oxidative stressors for fish (Cericato et al. 2008, 2009; Koakoski et al. 2014; Ferreira et al. 2010, 2012, 2013; Toni et al. 2011).

Fish depend on chemoreception to deal with many environmental challenges, such as finding food (Moyle and Cech 2000) and mates (Stacey and Sorensen 2005), aggregation or schooling (Sorensen and Stacey 1999), or avoiding predators (Døving et al. 2005). The execution of these behaviors is based on the logic of approaching or avoiding attractant or aversive stimuli. Animals can be attracted (Kessler et al. 2015) or repelled (Tierney et al. 2007) by toxic substances, and the deleterious effects that substances, such as GBH, ABH, and TBF, can impose may be more or less pronounced, acting as attractive or aversive chemical stimuli. Both attraction or aversion reactions have strong biological and toxicological significance. The risk of fish seeking contaminated sites is more direct and easy to perceive. Otherwise, fish that remain for longer periods in the presence of these substances (attractive or not perceived) tend to absorb higher concentrations than ones that escape from contaminated sites (aversive substance). Thus, in an environment contaminated with a substance with repellent properties, the fish will actively avoid the area, which, in turn, may change population dynamics and behavior.

For these reasons, our question is plausible, and to address it, we used adult zebrafish as the animal model for testing in a chamber that allows fish to escape from or seek a lane of TBF, $\mathrm{GBH}$, and $\mathrm{ABH}$ contaminated water.

\section{Methods}

\section{Ethical Note}

This study was approved by the Ethics Commission for Animal Use (CEUA) at Universidade de Passo Fundo, UPF, Passo Fundo, RS, Brazil (Protocol 29/2014-CEUA) and met the guidelines of Conselho Nacional de Controle de Experimentação Animal (CONCEA).

\section{Animals}

Adult (180 days) wild-type zebrafish (Danio rerio) of the short-fin (SF) strain, mixed-sex (50:50), were used as our stock population. The fish were fed twice a day, at 10:00 and 16:00 h, with commercial flaked food provided to satiation (Alcon ${ }^{\circledR}$ Basic, MEP 200 Complex, Brazil). The mean water temperature in the holding tank was maintained at $24 \pm 2{ }^{\circ} \mathrm{C}$, and the dissolved oxygen concentrations varied from 5.6 to $7.2 \mathrm{mg} / \mathrm{l}$. The $\mathrm{pH}$ values ranged from 6.2 to 7.4. The total ammonia-nitrogen concentration was less than $0.5 \mathrm{mg} / \mathrm{l}$.

\section{Agrichemicals Tested}

All chemicals were obtained from commercial suppliers. The agrichemicals that were used are a tebuconazole-based fungicide (Tebufort DVA, $200 \mathrm{~g} / \mathrm{l}$ of RS-1-p-chlorophenyl4,4-dimethyl-3-(1H-1,2,4-triazol-1-ylmethyl) pentan-3-ol, CAS\# 107534-96-3), glyphosate-based herbicide (Roundup Original $^{\mathrm{TM}}, 360 \mathrm{~g} / \mathrm{l}$ of $N$-phosphonomethylglycine, CAS\# 1071-83-6), and an atrazine-based herbicide (Siptram 500SC, $500 \mathrm{~g} / \mathrm{l}$ of 6-chloro- $\mathrm{N}_{2}$-ethyl- $\mathrm{N}_{4}$-isopropyl-1,3,5triazine-2,4-diamine, CAS\# 1912-24-9).

We chose an environmental concentration already related in the literature and $10 \%$ of a previously determined $\mathrm{LC}_{50-96 \mathrm{~h}}$. This percentile of $\mathrm{LC}_{50-96 \mathrm{~h}}$ was based on previous works in our laboratory using these specific contaminants (Kreutz et al. 2010). The nominal agrichemical concentrations in the water were confirmed by high-pressure liquid chromatography (HPLC) using the general methodology described by Zanella et al. (2003), along with specific methodologies for TBF (Zhao et al. 2008) and GBH (Hidalgo et al. 2004). The agrichemical concentrations and references are depicted in Table 1.

\section{Experimental Apparatus}

The experimental apparatus consisted of a 30-L acrylic tank (Fig. 1a; $50 \times 25 \times 25 \mathrm{~cm}$, length $\times$ width $\times$ height) as described in Abreu et al. (2016). Briefly, the apparatus had two chambers leading to two lanes of water with laminar flow running in parallel without mixing. A flow rate of $2 \mathrm{l} / \mathrm{min}$ was used for each track, and the manifold for each mixing chamber had a single door to allow for the introduction of the test substance.

\section{Experimental Protocol}

The basic strategy of the present study consisted of a twochoice test first used by Korver and Sprague (1989), then adapted to test anesthetics (Readman et al. 2013) and psychoactive drugs (Abreu et al. 2016), in which we quantified, in individually reared zebrafish, the choice for paths having contaminated or clean water flows. Choice was operationally set as the time spent in each path and the shuttle frequency between them. To conduct this choice test, fish from our stock tank were transferred to the experimental tank. After the transfer, fish were allowed to acclimate for $150 \mathrm{~s}$, and subsequently a dose of the test compound at a predetermined concentration was introduced into one of the mixing chambers for a period of 
Table 1 Nominal and measured concentrations of agrichemicals used

\begin{tabular}{lll}
\hline Substance (reference to environmental and LC50 concentrations) & \multicolumn{2}{l}{ Concentrations (mg/l) } \\
\cline { 3 - 3 } & Nominal & Measured (\%) \\
\hline GBH 10 \% CL50 (own data) & 5.2 & $5.148(99 \%)$ \\
GBH env. (Tierney et al. 2009) & 0.00659 & $0.006853(104 \%)$ \\
TBF 10 \% CL50 (Sánchez et al. 2012) & 26.8 & $26.07(97.3 \%)$ \\
TBF env. (Elsaesser and Schulz 2008) & 0.2 & $0.202(101 \%)$ \\
ABH 10 \% CL50 (Al-Sawafi and Yan 2013) & 1 & $1.03(103 \%)$ \\
ABH env. (Pratt et al. 1997) & 9.567 & $9.37566(98 \%)$ \\
\hline
\end{tabular}

A

\section{Plastic flux distributor}

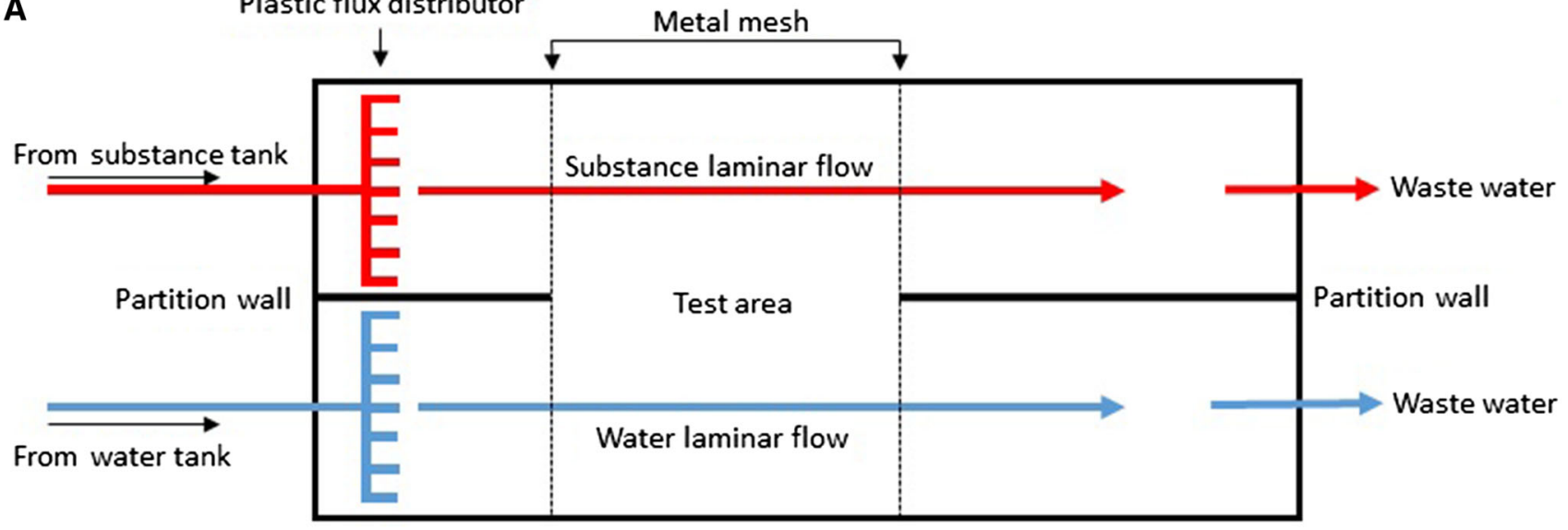

B

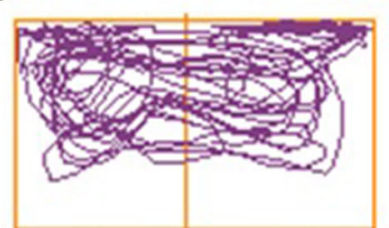

Negativecontrol

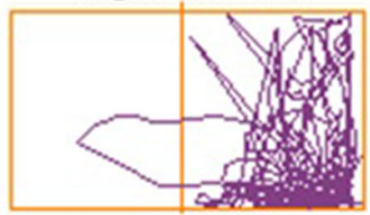

Positivecontrol

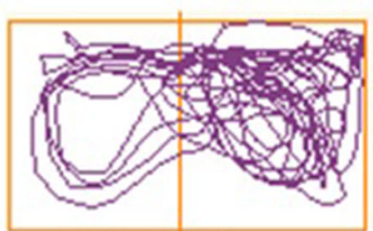

$\mathrm{ABH} 10 \% \mathrm{CL}$

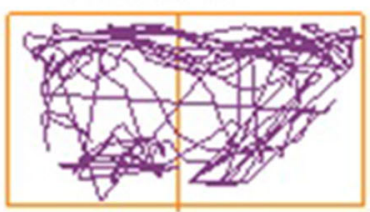

ABH Environm.

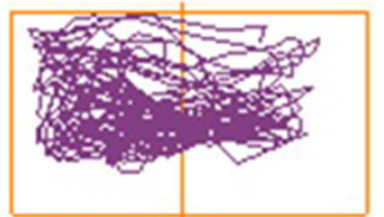

GBH $10 \% \mathrm{CL}$

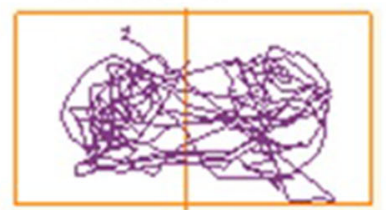

GBH Environm.

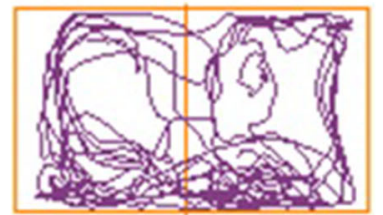

TBF $10 \% \mathrm{CL}$

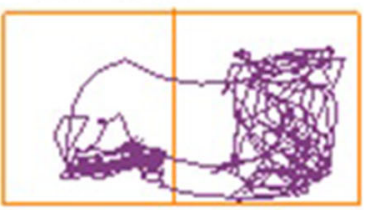

TBF Environm.

Fig. 1 a Schematic representation of the test chamber test. b The most representative video tracked movements of zebrafish

$150 \mathrm{~s}$ of exposure. This time was based on our previous work with psychoactive drugs residues (Abreu et al. 2016).

During the tests, fish were not fed. The position (left or right) of the clean and contaminated water lanes was switched between each of the trials to prevent a possible bias caused by a fish preference for the left or right lane. The horizontal gradient created by the laminar flow within the tank allowed the untreated lane to remain uncontaminated, creating two lanes between which the fish could move freely. Following each experiment with one fish, the system was flushed to remove any test substance residues. The fish behavior with access to both contaminated or clean water lanes was recorded via video camera for the whole experimental period. Ten zebrafish were evaluated 
for each contaminant. The video camera was positioned directly above the tank. The analyses of the video recordings were performed using AnyMaze $^{\circledR}$ (Stoelting CO, USA) and quantification lasted over the 150-s exposure period. Because the contaminated water flux rapidly filled all the test area, we did not consider this time in the $150 \mathrm{~s}$ of analysis.

Control observations were conducted to evaluate potential bias of the experimental tank. When fish were exposed to flows of clean water in both lanes, undistinguishable choice was observed for any lane of the apparatus. A positive control test was conducted by providing a lane with an acid water flow (hydrochloric acid solution at $\mathrm{pH}$ 3.0). In this case, zebrafish showed a clear aversion to acid water flow. They chose to stay in the clean water $(\mathrm{pH}$ 7) lane instead of the acid one: time spent in clean water was $118 \pm 6.2 \mathrm{~s}$ and in the acid water was $32 \pm 6.2 \mathrm{~s}$ ( $n=10 ; P=0.0039$; Wilcoxon matched-pairs signedrank test).

In each substance trial, the following locomotor parameters were evaluated: total distance traveled, mean speed, absolute turn angle, and the number of body rotations. All the parameters were evaluated during entire $150 \mathrm{~s}$, and additionally in five times fragments of $30 \mathrm{~s}$ to estimate choice preferences and locomotor activity across time.

\section{Statistics}

Homogeneity of variance was determined using Hartley's test, and normality was tested using the Bartlet test. The time spent in treated and control lanes were compared by paired Student's $t$ test or Wilcoxon matched-pairs signedrank test depending on data normality. Locomotor parameters were compared by Student's $t$ test or Mann-Whitney test (depending of normality and homogeneity tests) by contrasting the treatment lane values against the clean water control lane. Differences were considered statistically significant at $P$ values $<0.05$.

\section{Results}

The tested compounds (GBH, ABH, and TBF) did not alter water $\mathrm{pH}$ and DO levels (Table 2). Zebrafish spent significantly less time in the GBH-treated lane at the concentrations of $10 \%$ of $\mathrm{LC}_{50}$ (Wilcoxon matched-pairs signed-rank test; $P=0.0020$ ), suggesting an aversion response to this compound at this concentration (Fig. 2a). The same pattern of aversion was observed in the across-time analysis, except for the first $30 \mathrm{~s}$ of exposure. Regarding TBF environmental concentration, an aversion pattern was observed during a brief period of exposure (between $0-30 \mathrm{~s}$ and 30-60 s; Fig. 2b). No differences on time spent in untreated and contaminated lanes were found for $\mathrm{GBH}$ environmental concentration and both environmental and $10 \% \mathrm{LC}_{50}$ concentrations of TBF and ABH (Fig. 2a).

The results and the statistics of the tested locomotor parameters are depicted respectively in Fig. 3a, b. Briefly, GBH environmental concentration did not demonstrate diminished mean speed; however, in the analysis throughout the time, a decrease of speed was observed in the segments 0-30, 30-60, and 90-120 s. Regarding the number of body rotations, GBH environmental concentration also presented diminished values in the segments 30-60, 60-90, and 120-150 s. TBF showed decrease in mean speed in the first stage of exposure (0-30 s), and TBF environmental concentration showed elevated level of absolute turn angle in the segment 90-120 s. The remaining treatments did not show differences in any locomotor parameter.

\section{Discussion}

We showed that glyphosate-based herbicide was aversive to zebrafish except for the first $30 \mathrm{~s}$ of exposure. This suggests that the fish does not immediately avoid the contaminated water, but this avoidance is caused by a perception after a brief exposure to the substance. This
Table $2 \mathrm{pH}$ and dissolved oxygen $(\mathrm{mg} / \mathrm{l})$ levels in clean and contaminated water

\begin{tabular}{llllll}
\hline Substance & \multicolumn{2}{l}{$\mathrm{pH}$} & & \multicolumn{2}{l}{ Dissolved oxygen } \\
\cline { 2 - 3 } & Water & Substance & & Water & Substance \\
\hline Water (control) & $6.8 \pm 0.10$ & $6.8 \pm 0.07$ & & $6.2 \pm 0.05$ & $6.1 \pm 0.1$ \\
pH3 & $6.9 \pm 0.10$ & $3.0 \pm 0.10$ & & $5.7 \pm 0.10$ & $5.8 \pm 0.05$ \\
GBH 10 \% CL50 & $6.7 \pm 0.15$ & $7.0 \pm 0.06$ & & $5.9 \pm 0.10$ & $5.7 \pm 0.15$ \\
GBH env. & $6.7 \pm 0.10$ & $6.5 \pm 0.08$ & & $5.7 \pm 0.05$ & $5.6 \pm 0.10$ \\
TBF 10\% CL50 & $6.7 \pm 0.20$ & $7.0 \pm 0.05$ & & $5.6 \pm 0.10$ & $5.7 \pm 0.07$ \\
TBF env. & $7.4 \pm 0.10$ & $7.2 \pm 0.08$ & & $6.0 \pm 0.09$ & $6.2 \pm 0.14$ \\
ABH 10 \% CL50 & $7.0 \pm 0.10$ & $6.9 \pm 0.05$ & & $6.2 \pm 0.20$ & $6.0 \pm 0.08$ \\
ABH env. & $7.1 \pm 0.20$ & $7.3 \pm 0.08$ & & $6.1 \pm 0.09$ & $6.4 \pm 0.14$ \\
\hline
\end{tabular}

Data are expressed as mean \pm SEM of four water samples 


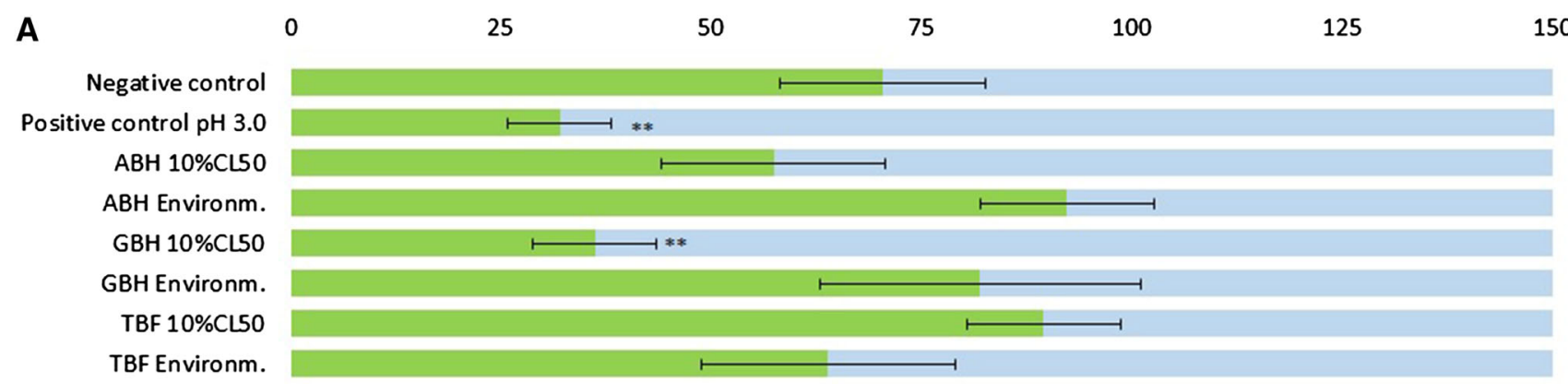

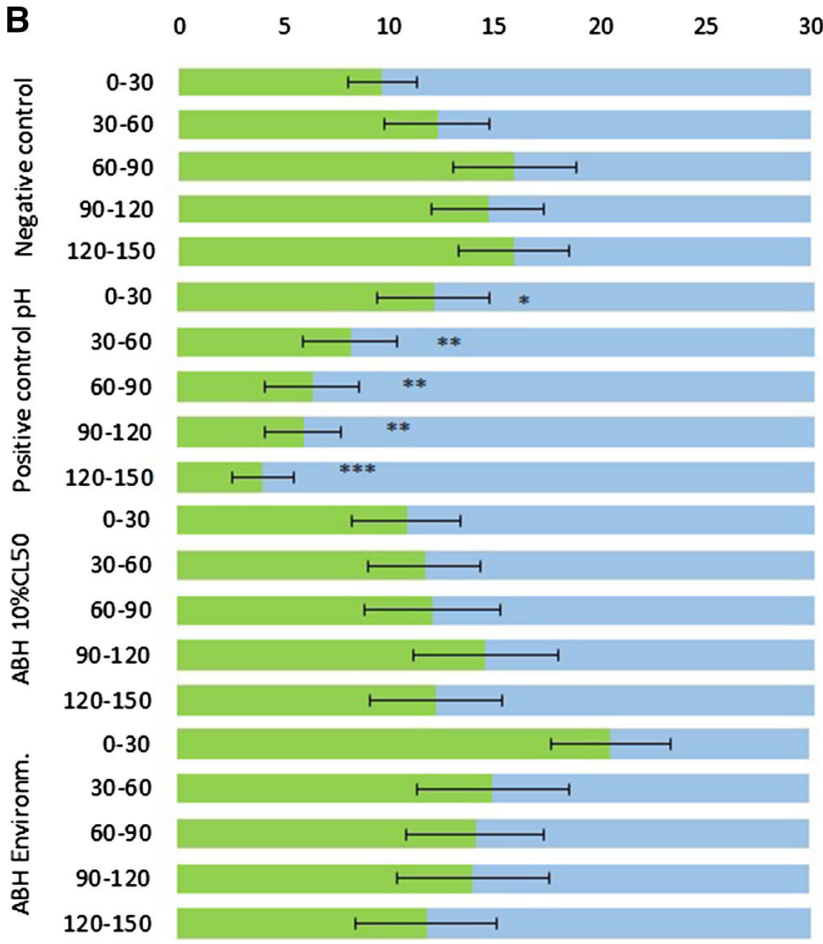

Fig. 2 a Time spent (s) in the substance or water lanes in a 150-s test. Data are expressed as the mean \pm SEM in each lane $(n=10)$. b Time spent (s) in the substance or water lanes in five period

latency to avoid the substance actively may be due to the chemical properties of GBH, which can be an irritant to fish, taking a longer period to cause disturbance. Tebuconazole-based fungicide provoked an aversion in the first segments, suggesting that the fish is desensitized throughout the exposure. Tebuconazole-based fungicide environmental concentration and atrazine-based herbicide neither attract nor repel zebrafish.

Thus, these chemical do not impose an extra toxic risk by being attractant to fish, although TBF and $\mathrm{ABH}$ can be deleterious, because they induce no aversive response. Because the uptake and bioaccumulation of chemicals in fish seems to be time- and dose-dependent (Hamelink and Spacie 1977; Geyer et al. 2000; Paterson and Metcalfe 2008), a fish that remains for an extended time in the

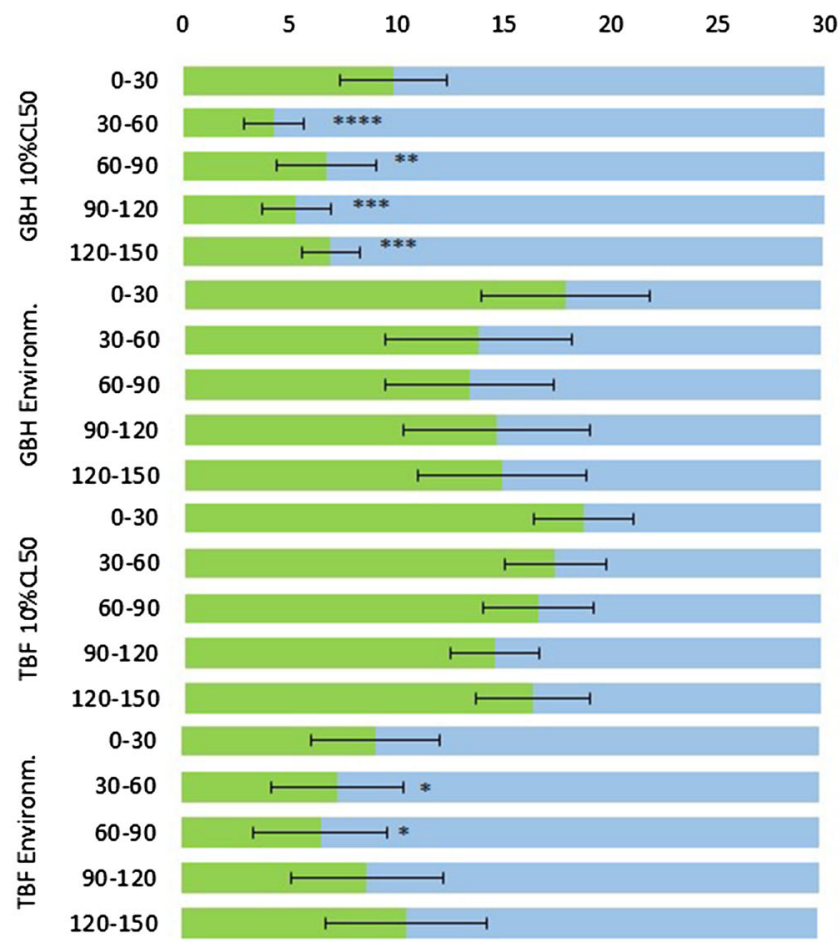

fragments of $30 \mathrm{~s}$. Means were compared by the paired $t$ test or Wilcoxon matched-pairs signed-rank test $(* P<0.05, * * P<0.01$, $* * * P<0.001$, and $* * * * P<0.0001)$

presence of these drugs (attractive or not perceived drugs) tend to absorb higher concentrations than ones that escape from contaminated sites (aversive drugs).

The protocol and apparatus of this chemotaxic preference test was previously validated to evaluate aversion of fish anesthetics (Readman et al. 2013) as well psychotropic drug residues (Abreu et al. 2016). In this and former studies, the positive control test with hydrochloric acid was clearly aversive to zebrafish and that they display strong avoidance behavior, showing the ability of zebrafish to detect the acid $\mathrm{pH}$ by its chemosensory traits. In the waterwater control, no choice between apparatus lane was observed. These evidences show that zebrafish respond to chemical stimulus displaying place choice and the test apparatus has no bias. Thus, any behavioral change can be 
A
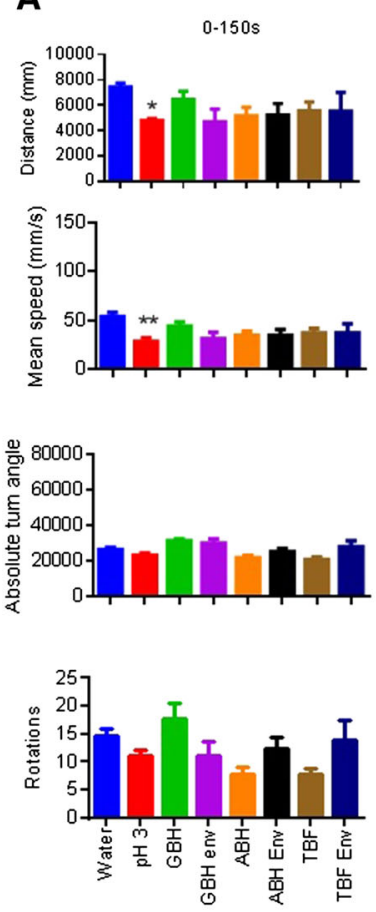

B

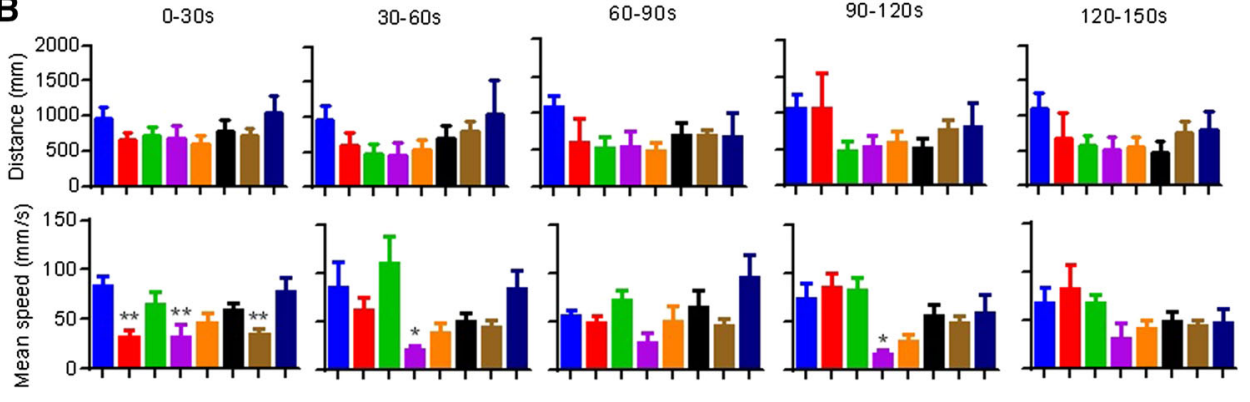

Fig. 3 a Locomotor activity of zebrafish during the 150-s test, and b locomotor activity of zebrafish in five period fragments of $30 \mathrm{~s}$. Data are expressed as mean $\pm \operatorname{SEM}(n=10)$. $G B H$ glyphosate-based herbicide, $T B F$ tebuconazole-based fungicide, $A B H$ atrazine-based herbicide. Asterisks indicate differences between each substance/ concentration against the water control (clean line). One-way Anova followed by Dunnet test or Kruskal-Wallis test depending on the normality (Bartlet) and homogeneity of variance (Hartley) tests, $* P<0.05, * * P<0.01, n=7-10$

containing glyphosate provoked attraction for zebrafish (Tierney et al. 2009). In our study, this same concentration of glyphosate found in the pesticide mixture used by Tierney et al. (2009) did not provoke aversion neither attraction. It is important to take in account that, in these studies (Tierney et al. 2009; Strieck 1924; Hidaka and Tatsukawa 1989; Folmar et al. 1979; Morgan et al. 1991), the test methodology are very different from the one proceed in the present study. These methodology differences might affect the results.

The speed was significantly affected by GBH in the first minute of exposure, presenting diminished values. Tierney et al. (2007) also demonstrated that glyphosate exposure can induce a reduction of fish locomotion. Regarding the number of rotations, this parameter also was reduced, suggesting that fish become desensitized to the GBH locomotor effects over the exposure period. Only the higher concentration of TBF provoked an increase in the absolute turn angle for a brief moment. Those high turn angles would suggest possible neuromuscular effects, because the absolute turn angle is a sensitive measure of motor coordination (Blazina et al. 2013). The altered locomotor coordination might be a possible causation factor of the not-aversive response of zebrafish against this agrichemical, where the fish is not capable of escaping the affected area. 
We found that fish did not avoid ABH and TBF contaminated sites probably by absence of perception of these compounds in the specific concentrations and/or changes in locomotor activity (Fig. 3a, b). This absence of detection/ reaction might be dangerous, because fish did not move away from contaminated sites. The changes in locomotor parameters provoked by GBH and TBF reinforce our conclusion that these compounds are dangerous, because fish did not avoid contaminated areas by not perceiving the drugs or due to locomotor and/or neuromuscular impairments.

Regarding GBH, despite the well-related negative effects (Cericato et al. 2009, 2008; Koakoski et al. 2014; Ferreira et al. 2010, 2012, 2013; Toni et al. 2011; Jiraungkoorskul et al. 2002; Langiano and Martinez 2008; Glusczak et al. 2007; Armiliato et al. 2014) fish actively avoided contaminated sites if concentrations were higher than $10 \%$ of LC50. This fact represents a defensive behavior that can protect fish from the deleterious effects of GBH. However, avoidance/aversive behavior in a location where fish have no escape to avoid this chemical might be an unavoidable stress source with potentially harmful effects.

The concentrations used were very plausible in terms of contamination of natural water bodies and fishponds. In addition, the GBH is used directly in water bodies to control aquatic macrophytes. Even TBF and $\mathrm{ABH}$, which are not used directly in water, can easily reach the water bodies in small concentrations as a result of leaching by rain or as a result of accidents (Soumis et al. 2003) causing harmful effects to fish. In addition, aquatic organisms may be exposed to accidental spills of pollutants, incorrect discharges of substances or contaminants already present in the water. Such contamination may cause biomagnification, in which concentrations much higher than those found in the environment may be observed. This phenomenon has been reported for the presence of pesticides (Niethammer et al. 1984; Kelly et al. 2007; Goerke et al. 2004).

Finally, a limitation of this study is that we cannot directly extrapolate these results to the aquatic environment, where fish are chronically exposed to xenobiotics since early development, and in this study, fish were briefly exposed to the agrichemicals. However, this does not lessen the importance of our results, because data about the attraction/aversion paradigm related to agrichemical exposures are very scarce. In addition, the attraction/aversion paradigm might be an innovative and interesting approach in toxicological studies.

Acknowledgments This study was funded by the Universidade de Passo Fundo and CNPq. L.J.G.B. holds a CNPq research fellowship (301992/2014-2).

Author Contributions The funders had no role in study design, data collection and analysis, decision to publish, or preparation of the manuscript. L.J.G.B., M.S.A, R.E.B., and J.G.S.R. conceptualized the study, interpreted the data, and wrote the paper. M.S.A., A.C.V.G., G.K., F.K., T.A.O., and H.H.A.B. collected and analyzed the data.

\section{Compliance with Ethical Standards}

Conflict of interest The authors declare no competing financial interests.

\section{References}

Abreu MS, Giacomini ACV, Gusso D, Rosa JGS, Koakoski G, Kalichak F, Idalencio R, Oliveira TA, Barcellos HHA, Bonan CD, Barcellos LJG (2016) Acute exposure to waterborne psychoactive drugs attracts zebrafish. Comp Biochem Physiol C 179:37-43. doi:10.1016/j.cbpc.2015.08.009

Al-Sawafi AGA, Yan Y (2013) Bioconcentration and antioxidant status responses in zebrafish (Danio rerio) under atrazine exposure. Int J Chem Eng Appl 4:204-208. doi:10.7763/ IJCEA.2013.V4.295

Armiliato N, Ammar D, Nezzi L, Straliotto M, Muller YMR, Nazari EM (2014) Changes in ultrastructure and expression of steroidogenic factor-1 in ovaries of zebrafish Danio rerio exposed to glyphosate. J Toxicol Environ Health A 77:405-414. doi:10. 1080/15287394.2014.880393

Blazina AR, Vianna MR, Lara DR (2013) The spinning task: a new protocol to easily assess motor coordination and resistance in zebrafish. Zebrafish 10:480-485. doi:10.1089/zeb.2012.0860

Cericato L, Neto JGM, Fagundes M, Kreutz LC, Quevedo RM, Finco J, Rosa JGS, Koakoski G, Centenaro L, Pottker E, Anziliero D, Barcellos LJG (2008) Cortisol response to acute stress in jundia (Rhamdia quelen) acutely exposed to sublethal concentrations of agrichemicals. Comp Biochem Physiol C 148:281-286. doi:10. 1016/j.cbpc.2008.06.008

Cericato L, Neto JGM, Kreutz LC, Quevedo RM, Rosa JGS, Koakoski G, Centenaro L, Marqueze A, Barcellos LJG (2009) Responsiveness of the interrenal tissue of jundia (Rhamdia quelen) to an in vivo $\mathrm{ACTH}$ test following acute exposure to sublethal concentrations of agrichemicals. Comp Biochem Physiol C 149:363-367. doi:10.1016/j.cbpc.2008.09.002

Døving KB, Hamdani EH, Hoglund E, Kasumyan A, Tuvikene AO (2005) Review of the chemical and physiological basis of alarm reactions in cyprinids. In: von der Emde G, Mogdans J, Kapoor BG (eds) Senses of fish. Narosa, New Delhi, pp 131-163

Elsaesser D, Schulz R (2008) Mitigation of fungicide pollution in vegetated agricultural surface waters: GIS modeling and monitoring in the field. In: Conference proceeding from the SETAC Europe 18th annual meeting. SETAC, Warsaw, pp 406-407

Ferreira D, Motta AC, Kreutz LC, Toni C, Loro VL, Barcellos LJG (2010) Assessment of oxidative stress in Rhamdia quelen exposed to agrichemicals. Chemosphere 79:914-921. doi:10. 1016/j.chemosphere.2010.03.024

Ferreira D, Unfer TC, Rocha HC, Kreutz LC, Koakoski G, Barcellos LJG (2012) Antioxidant activity of bee products added to water in tebuconazole-exposed fish. Neotrop Ichthyol 10:215-220. doi:10.1590/S1679-62252012000100021

Ferreira D, Rocha HC, Kreutz LC, Loro VL, Marqueze A, Koakoski G, Rosa JGS, Gusso D, Oliveira TA, Abreu MS, Barcellos LJG (2013) Bee products prevent agrichemical-induced oxidative damage in fish. PLoS ONE 8(10):e74499. doi:10.1371/journal. pone.0074499

Folmar LC, Sanders HO, Julin AM (1979) Toxicity of the herbicide glyphosate and several of its formulations to fish and aquatic invertebrates. Arch Environ Contam Toxicol 8:269-278. doi:10. 1007/BF01056243 
Geyer HJ, Rimkus GG, Scheunert I, Kaune A, Schramm K, Kettrup A, Zeeman M, Muir DCG, Hansen LG, Mackay D (2000) Bioaccumulation and occurrence of endocrine disrupting chemicals (EDCs), persistent organic pollutants (POPs), and other organic compounds in fish and other organisms including humans. In: Beek B (ed) The handbook of environmental chemistry, bioaccumulation. Springer, Berlin, p 166

Glusczak L, Miron DS, Moraes BS, Simões RR, Schetinger MRC, Morsch VM, Loro VL (2007) Acute effects of glyphosate herbicide on metabolic and enzymatic parameters of silver catfish (Rhamdia quelen). Comp Biochem Physiol C 146:519524. doi:10.1016/j.cbpc.2007.06.004

Goerke H, Weber K, Bornemann H, Ramdohr S, Plötz J (2004) Increasing levels and biomagnification of persistent organic pollutants (POPs) in Antarctic biota. Mar Poll Bull 48:295-302

Hamelink JL, Spacie A (1977) Fish and chemicals: the process of accumulation. Ann Rev Pharmacol Toxicol 17:167-177. doi:10. 1146/annurev.pa.17.040177.001123

Hidaka H, Tatsukawa R (1989) Avoidance by olfaction in a fish, Medaka (Oryzias latipes), to aquatic contaminants. Environ Poll 56:299-309. doi:10.1016/0269-7491(89)90075-4

Hidalgo C, Rios C, Hidalgo M, Salvado V, Sancho JV, Hernández F (2004) Improved coupled-column liquid chromatographic method for the determination of glyphosate and aminomethylphosphonic acid residues in environmental waters. J Chromatogr A 1035:153-157. doi:10.1016/j.chroma.2004.02.044

Jiraungkoorskul W, Upatham ES, Kruatrachue M, Sahaphong S, Vichasri-Grams S, Pokethitiyook P (2002) Histopathological effects of Roundup, a glyphosate herbicide, on Nile tilapia (Oreochromis niloticus). Sci Asia 28:121-127

Kelly BC, Ikonomou MG, Blair JD, Morin AE, Gobas FAPC (2007) Food web-specific biomagnification of persistent organic pollutants. Science 317:236-239

Kessler D, Kallenbach M, Diezel C, Rothe E, Murdock M, Baldwin IT (2015) How scent and nectar influence floral antagonists and mutualists. eLife 4:e07641. doi:10.7554/eLife.07641

Koakoski G, Quevedo RM, Ferreira D, Oliveira TA, Rosa JGS, Abreu MS, Gusso D, Marqueze A, Kreutz LC, Giacomini ACV, Fagundes M, Barcellos LJG (2014) Agrichemicals chronically inhibit the cortisol response to stress in fish. Chemosphere 112:85-91. doi:10.1016/j.chemosphere.2014.02.083

Korver RM, Sprague JB (1989) Zinc avoidance by fathead minnows (Pimephales promelas): computerized tracking and greater ecological relevance. Can J Fish Aquat Sci 46:494-502. doi:10.1139/f89-066

Kreutz LC, Barcellos LJG, Marteninghe A, dos Santos ED, Zanatta R (2010) Exposure to sublethal concentration of glyphosate or atrazine-based herbicides alters the phagocytic function and increases the susceptibility of silver catfish fingerlings (Rhamdia quelen) to Aeromonas hydrophila challenge. Fish Shellfish Immunol 29:694-697. doi:10.1016/j.fsi.2010.06.003

Langiano VM, Martinez CBR (2008) Toxicity and effects of a glyphosate-based herbicide on the neotropical fish, Prochilodus lineatus. Comp Biochem Physiol C 147:222-231. doi:10.1016/j. cbpc.2007.09.009

Lebokowska MZ, Radziwill M, Narozniak AR, Kobiela S (2003) Toxicity assessment of wood preservatives. Environ Int 28:801-802. doi:10.1016/S0160-4120(02)00113-7

Morgan JD, Vigers GA, Farrell AP, Janz DM, Manville JF (1991) Acute avoidance reactions and behavioral responses of juvenile rainbow trout (Oncorhynchus mykiss) to Garlon $4^{\circledR}$, Garlon $3^{\circledR}$ and Vision ${ }^{\circledR}$ herbicides. Environ Toxicol Chem 10:73-79. doi:10.1002/etc.5620100109

Moyle PB, Cech JJ (2000) Fishes: an introduction to ichthyology, 4th edn. Prentice Hall Canada Inc., Toronto
Niethammer KR, White DH, Baskett TS, Sayre MW (1984) Presence and biomagnification of organochlorine chemical residues in oxbow lakes of Northeastern Louisiana. Arc Environ Contam Toxicol 13:63-74

Paterson G, Metcalfe CD (2008) Uptake and depuration of the antidepressant fluoxetine by the Japanese medaka (Oryzias latipes). Chemosphere 74:125-130. doi:10.1016/j.chemosphere.2008.08. 022

Pratt JR, Melendez AE, Barreiro R, Bowers NJ (1997) Predicting the ecological effects of herbicides. Ecol Appl 7:1117-1124. doi:10. 2307/2641200

Readman GD, Owen SF, Murrell JC, Knowles TG (2013) Do fish perceive anesthetics as aversive? PLoS ONE 8(9):e73773. doi:10.1371/journal.pone.0073773

Sánchez AO, Paraíba LC, Jonsson CM, Carrasco JM (2012) Acute toxicity and bioconcentration of fungicide tebuconazole in zebrafish (Danio rerio). Environ Toxicol 27:109-116. doi:10. 1002/tox.20618

Sorensen PW, Stacey NE (1999) Evolution and specialization in fish hormonal pheromones. In: Johnston RE, Müller-Schwarze D, Sorensen PW (eds) Advances in chemical signals in vertebrates. Plenum, New York, pp 15-48

Soumis N, Lucotte M, Sampaio D, Almeida DC, Giroux D, Morais S, Pichet P (2003) Presence of organophosphate insecticides in fish of the Amazon river. Acta Amazon 33:325-338. doi:10.1590/ 1809-4392200332338

Stacey NE, Sorensen PW (2005) Hormones, pheromones, and reproductive behaviors. In: Sloman KS, Balshine S, Wilson RW (eds) Behaviour: interactions with fish physiology (24). In: Hoar WS, Randall DJ, Farrell AP (series eds) Fish physiology. Academic, New York, pp 359-412

Strieck F (1924) Untersuchungen über den Geruchsund Geschmackssinn der Ellritze (Phoxinus laevis A.). J Comp Physiol A 2:122-154. doi:10.1007/BF00339042

Tierney KB, Singh CR, Ross PS, Kennedy CJ (2007) Relating olfactory neurotoxicity to altered olfactory-mediated behaviors in rainbow trout exposed to three currently-used pesticide. Aquat Toxicol 81:55-64

Tierney KB, Sekela MA, Cobbler CE, Xhabija B, Gledhill M, Ananvoranich S, Zielinski BS (2009) Evidence for behavioral preference toward environmental concentrations of urban-use herbicides in a model adult fish. Environ Toxicol Chem 9999:1-9. doi:10.1002/etc.588

Toni C, Ferreira D, Kreutz LC, Loro VL, Barcellos LJG (2011) Assessment of oxidative stress and metabolic changes in common carp (Cyprinus carpio) acutely exposed to different concentrations of the fungicide, tebuconazole. Chemosphere 83:579-584. doi:10.1016/j.chemosphere.2010.12.022

Vera MS, Lagomarsino L, Sylvester M, Pérez GL, Rodríguez P, Mugni H, Sinistro R, Ferraro M, Bonetto C, Zagarese H, Pizarro $\mathrm{H}$ (2010) New evidences of Roundup (glyphosate formulation) impact on the periphyton community and the water quality of freshwater ecosystems. Ecotoxicology 19:710-721. doi:10.1007/ s10646-009-0446-7

Zanella R, Primel EG, Goncalves FF, Kurtz MHS, Mistura CM (2003) Development and validation of a high-performance liquid chromatographic procedure for the determination of herbicide residues in surface and agriculture waters. J Sep Sci 26:935-938. doi:10.1002/jssc. 200301309

Zhao YG, Zhang Y, Zhang BB, Hu GJ, Zhang XZ, Zhou CH, Li J (2008) Determination of tebuconazole in water using solid phase extraction and HPLC. China National Knowl Infrastruct J 47(4):271 